\title{
Tourism Partnerships in Protected Areas: Exploring Contributions to Sustainability
}

\author{
Sharron L. Pfueller • Diane Lee · Jennifer Laing
}

Received: 10 July 2010/Accepted: 8 July 2011/Published online: 11 August 2011

(c) The Author(s) 2011. This article is published with open access at Springerlink.com

\begin{abstract}
Partnerships between natural-area managers and the tourism industry have been suggested to contribute to sustainability in protected areas. This article explores how important sustainability outcomes of partnerships are to their members, how well they are realised and the features of partnerships leading to their achievement. In 21 case studies in Australia, interviews $(n=97)$ and surveys $(n=100)$ showed that of 14 sustainability outcomes, improved understanding of protected areas values and improved biodiversity conservation were the most important. Other highly ranked outcomes were greater respect for culture, heritage, and/or traditions; improved quality of environmental conditions; social benefits to local communities; and improved economic viability of the protected area. Scores for satisfaction with outcomes were, like those for importance, all high but were less than those for importance for the majority, with improvement in quality of environmental conditions showing the largest gap. The satisfaction score exceeded that for importance only for increased competitiveness of the protected area as a tourist destination. "Brown" aspects of sustainability, i.e., decreased waste or energy use, were among the lowest-scoring outcomes for both importance and satisfaction. The most important factor enabling
\end{abstract}

\section{S. L. Pfueller $(\square)$}

School of Geography and Environmental Science,

Monash University, Melbourne, VIC 3800, Australia

e-mail: sharron.pfueller@arts.monash.edu.au

D. Lee

School of Social Sciences and Humanities, Murdoch University, Murdoch, WA, Australia

\section{J. Laing}

Australia International Tourism Research Unit,

Department of Management, Berwick, VIC, Australia sustainability outcomes was provision of benefits to partnership members. Others were increased financial support, inclusiveness, supportive organisational and administrative arrangements, direct involvement of decision makers, partnership maturity, creation of new relationships, decreased conflict, and stimulation of innovation. Improving sustainability outcomes, therefore, requires maintaining these partnership attributes and also increasing emphasis on reducing waste and resource use.

Keywords Conservation - Natural resources ·

Partnerships · Protected areas · Sustainability · Tourism

\section{Introduction}

This article aims to explore the sustainability goals of partnerships between tourism, protected-area managers, and communities. It examines partner satisfaction with sustainability outcomes, investigates if satisfaction accords with the importance ascribed to the outcomes, and analyses the characteristics of partnerships that contribute to realisation of outcomes.

Achieving sustainability goals involves balancing ecological, social, and economic development outcomes (World Commission on Environment and Development [WCED] 1987). The world movement to create national parks in areas of ecological value was an attempt to protect natural areas from consumptive uses, such as logging, hunting, and agriculture. Because of their unique character and beauty, these areas have become attractions for tourism and recreation that do not involve the destruction associated with other uses. This idea has led natural-area managers to regard these activities as providing justification, income, and resources for conservation and environmental 
management (Leslie 1986; Murphy 1986). Nevertheless, tourism and recreation have a range of damaging impacts on habitats and species (Butler 1980; Buckley and Pannell 1990). The advent of ideas of sustainability has led to attempts to create alternative forms of tourism that have fewer impacts on the environment and communities (Eadington and Smith 1992). One such form is ecotourism, which occurs in natural areas and combines the goals of optimising social and ecological outcomes, providing contributions to local communities, and fostering environmental awareness among visitors (Ceballos-Lascurain 1987). A more generic term, "sustainable tourism" describes tourism that occurs in any setting but aims to be responsible in line with sustainable development.

Regardless of the type of visitor experience they offer, tourism operators who conduct business in protected areas must abide by the requirements of natural-area managers in terms of areas they can access as well as types of activity and impacts they can offer and therefore must embrace aspects of sustainability. In Australia, this was formalized in the Australian Governments White Paper on Tourism (Commonwealth of Australia 2003), in which there is a requirement for development of partnerships between the tourism industry and protected-area management. However, the underlying goals of these partners are somewhat different, with protected-area managers focusing on biodiversity conservation and tourism operators focusing on providing a visitor experience that yields economic profit. Although many such partnerships have been operating for considerable periods of time around the world, little is known about their success in terms of approaches to conservation and protected-area management.

\section{Sustainability, Sustainable Development, and Tourism}

Although the concept of sustainability is relative and mutable (Wahab and Pigram 1997), the starting point for understanding sustainable development is usually the definition developed by the WCED in the Brundtland Report (WCED 1987, p. 4): “... development that meets the needs of the present without compromising the ability of future generations to meet their own needs," which links the notions of conservation and stewardship (Pigram and Wahab 1997) and recognizes both human and conservation dimensions. The definition adopted by the United Nations Environmental Programme (UNEP), the World Conservation Union, and the World Wide Fund for Nature"improving the quality of human life while living within the carrying capacity of supporting ecosystems" (IUCN/ UNEP/WWF 1991) —also goes beyond environmental concerns. A global desire to commit to broad sustainability principles led to the creation of Agenda 21 (UNCED 1993, p. 28), which was designed to achieve "a global partnership for sustainable development" and focused on goals of "fulfillment of basic needs, improved living standards for all, better protected and managed ecosystems and a safer, more prosperous future (UNCED 1993, p. 28)." This definition covers environmental, economic and socio-cultural goals, the so-called three pillars of the triple bottom-line approach to sustainability (Deery and others 2005; Dwyer 2005; Font and Harris 2004).

In some natural areas, sustainability goals may only be achieved by the total absence of tourism (Hunter 1997), but in other areas tourism can be viewed as contributing to sustainable development and sustainability (Björk 2007; Wall 1997). This latter type of tourism aims for "a tourism that will carry on, that will endure but that will also contribute, nourish and tolerate" (Macbeth 1994, p. 42). However, applying the principles of sustainable development in the context of tourism is challenging and even problematic (Butler 1999, p. 11). This is partly the result of the impreciseness of the terms "sustainability" and "sustainable tourism," which has been noted in the literature (Butler 1999; Macbeth 1994; McCool and others 2001; Sharpley 2000; Wall 1997), as well as the need to understand how the two concepts interrelate and can be married in a practical as well as a philosophic sense. Thus, there is no universally accepted definition of sustainable tourism that has "become all things to all interested parties" (Butler 1999). Wheeller (1993) suggests that from a tourist perspective, the concept of sustainable tourism essentially provides nothing more than a warm glow to the heart "while enjoying oneself" (Butler 1999). More positive views are that sustainable development is important in setting both "the moral agenda" and "a practical route map" for sustainable tourism (Macbeth 1994, p. 42) and that sustainable tourism "recognises that a precise definition of sustainable tourism is less important than the journey toward it" (Hardy and Beeton 2001, p. 172).

There are, nevertheless, some common threads running through attempts to conceptualise sustainable tourism. These include the notion of engaging in behaviour that does not have adverse future effects or consequences (Butler 1993; Faulkner 2001; Hardy and Beeton 2001; Macbeth 1994; World Tourism Organisation [WTO] 1993). There is also recognition of the needs of different stakeholders (Butler 1999; Faulkner 2001; Hardy and Beeton 2001; Murphy and Price 2005) and the importance of engaging them in this process. Faulkner (2001, p. 344) suggests that sustainable-tourism development "achieves equity in the distribution of costs and benefits of tourism between different segments of the community and between the current and future generations." Another common theme is the need to integrate a variety of goals, usually economic, environmental, social, and cultural (Murphy and 
Price 2005; Wight 1993). There is also an acknowledgment that tourism development has limits (Bramwell and others 1996; Butler 1996, 1999; Cooper 1996; Payne 1993) and that the boundaries of acceptability with respect to change must be judged by stakeholders (Gössling and others 2002; Murphy and Price 2005; Sun and Walsh 1998; Wearing and Neil 1999). Some definitions, such as the agenda for sustainable tourism developed by UNEP and the WTO (UNEP/WTO 2005), focus on outcomes. The 12 aims in this agenda, using Macbeth's (1994) four categories, are (1) economic sustainability (economic viability, local prosperity, employment quality); (2) social sustainability (social equity, visitor fulfilment, local control, community wellbeing); (3) cultural sustainability (cultural richness); and (4) ecological sustainability (physical integrity, biological diversity, resource efficiency, and environmental purity).

\section{Partnerships}

During the last two decades, natural-area management has increasingly moved from purely scientifically based biodiversity conservation to approaches, such as ecosystem and watershed management, that embrace the broader concepts of sustainability and sustainable development (Slocombe 1993) and involve participation of associated communities and interests (Kapoor 2001; Leach and Pelkey 2001). Even although tourism is a commercial activity requiring economic returns to survive, within partnerships with protected-area managers, it appears to contribute to sustainability (De Lacy and others 2002; Selin 1999; Robinson 1999; Macbeth and others 2004).

It is recognized that it is important for the tourism industry to enter into dialogue and partnership with other groups and sectors to achieve true sustainability goals (Butler 1999; Goodwin 1996; Jones and Burgess 2005; Robinson 1999; Selin 1999; Wall 1997). This reflects the understanding of sustainable tourism as integrating the needs of different interests and stakeholders (Butler 1999; Faulkner 2001; Hardy and Beeton 2001; Robinson 1999) and acknowledges equity concerns (Hall 1999; Jones and Burgess 2005). It is important that stakeholders participate willingly in the process (Butler 1999) and that there is agreement on sustainability goals as well as on how to achieve them (McCool and others 2001). Dudley and others (1999) make the same point in the protected-area context. A collaborative or partnership approach is believed to be more likely to lead to decisions being implemented because the stakeholders will have more ownership of the process and any plans arising from them (Hall 1999).
Evaluating sustainability outcomes of tourism partnerships with protected areas is challenging (Butler 1999; Murphy and Price 2005), mainly because every destination will have a different balancing point with respect to resource preservation versus development; thus, developing consistent criteria across destinations may be impossible (Tsaur and others 2005). There have, however, been attempts to identify what tourism should sustain. The tourism and recreation industry in Montana ranked natural and cultural heritage, community economic stability, quality of life, and unique natural environment as the most important components (McCool and others 2001). Other studies have proposed indicators for sustainable management of visitor use of protected areas (Tonge and others 2005) or a framework for developing social and socioeconomic indicators for measuring the impact of tourism on communities (Deery and others 2005). Another suggestion is that a key indicator of sustainable tourism should be based around the ecological footprint that would show a total estimate of demands on the biophysical-productivity and waste-assimilation capacities of the nature of the area (Hunter and Shaw 2005).

Partnerships have a number of outcomes in both naturalresource management and tourism contexts. They can act as a vehicle for mobilising resources and skills, leading to efficiency and productivity gains (De Lacy and others 2002). They can also support change management (Rosenau 2000), stimulate innovation (Tremblay 2000), moderate power inequalities (Leach and Pelkey 2001), boost conservation initiatives (Stubbs and Specht 2005), foster collaborative decision-making and conflict resolution (De Lacy and others 2002), and assist with coordination and understanding (Davidson and Lockwood 2008). However, partnerships have negative outcomes in some instances. They can be exclusionary, favour established interests (Rhodes 1997), compromise public accountability, and threaten public values and the capacity of governments to govern (Davidson and Lockwood 2008). Efforts in recent years have focused on partnership success and the factors that influence this, largely in terms of the success of outcomes (Blackman and others 2004; Buckley and Sommer 2001; De Lacy and others 2002; Griffin and Vacaflores 2004; Moore 1996; Wondolleck and Yaffee 2000). With respect to outcomes, asking members of the partnership to define success has merit given their involvement in and intimate understanding of the partnership (Moore 1996).

Studies on outcomes of partnerships in Australian natural or protected areas to date have showed a lack of concern about "brown" outcomes, such as decreased production of waste by tourism enterprises and visitors and decreased use of energy (Tonge and others 2005). They highlight an interest in efficiency and productivity outcomes (Buckley and Sommer 2001; De Lacy and others 
2002), minimisation of conflict (De Lacy and others 2002), economic support of parks (Steffen 2003), better tourist infrastructure as well as assets and products (Steffen 2003), greater quality visitor experiences (Steffen 2003; Griffin and Vacaflores 2004; Tourism and Transport Forum [TTF] Australia 2004), and public education and heightened appreciation for the need for conservation (Steffen 2003; TTF Australia 2004). Some of these studies, however, involve a few cases or draw together cases without an overarching analytical framework to guide future research, and many have used a qualitative rather than mixedmethods approach (e.g., Bingham 1986; Leach and Pelkey 2001; Moore and Lee 1999; Saxena 2005). They also do not specifically address contributions of partnerships to sustainability. In a broad study of tourism partnerships that focused on assessment of the relative and collective contribution of eight theoretical frameworks in identifying their most important features and outcomes, Laing and others (2009) observed that partners nominated improved understanding of values of protected areas, improved biodiversity conservation, and greater respect for culture, heritage, and/or traditions as the most important outcomes for sustainability. The research reported here extends that study by exploring in depth the sustainability outcomes, examining partners' satisfaction with the realisation of sustainability goals, and exploring, in detail, the characteristics of partnerships that were related to their achievement.

\section{Methods}

\section{Case Studies}

This research employed a multiple case-study approach to permit both literal and theoretical replication (Yin 2003) using both quantitative and qualitative methods as described by Laing and others (2009). Theoretical replication was enabled by including contrasting cases and literal replication by the inclusion of cases with common features and similar outcomes. Selection of case studies from the states of Victoria, South Australia, Western Australia, and Tasmania was based on 16 criteria (Table 1) established on the basis of features shown in previous research to be influential in partnerships and with input from an industry reference group. This group consisted of 12 middle- to senior-level managers in both state and federal protectedarea agencies, state tourism organizations, e.g., Tourism Victoria, and senior members of the tourism industry and associated bodies, e.g., TTF Australia. The final set of 21 case studies included at least 1 case that demonstrated each criterion.
Table 1 Case study—selection criteria

Marine and terrestrial partnerships (not both but examples of each)

Partnerships with both many and few members

Government and nongovernment protected-area partnerships with or to provide tourism

Partnerships with large and small tour operations

Cover different facets of tourism (access, accommodation, attractions, activities, and amenities)

Partnerships associated with protected areas with significant infrastructure development as well as those with no infrastructure development

Formal (legal statutory or written base) and informal (none of these) partnerships

Best-practice examples from each state and territory (at least one from each) where there has been a successful outcome, and three examples (at least) from each of Victoria, Tasmania, and Western Australia

At least one partnership from Victoria, Tasmania, and Western Australia that has had problematic elements

At least one indigenous partnerships case study

At least one urban or periurban protected area involved in a tourism partnership

Partnerships including regional planning authorities and/or local government

Joint planning for and management of protected areas (e.g., transboundary parks)

Partnerships resulting from community-based initiatives

Partnerships in potentially high-conflict locales (e.g., marine parks, periurban protected areas, old-growth forests, and wilderness areas)

\section{Sampling Method}

Potential respondents from each case study were selected and identified as affiliated or familiar with the partnership, e.g., through employment or participation. A researcher contacted potential respondents by mail or telephone to explain the research and to request their participation. An explanatory letter and a questionnaire were sent to each respondent, and an interview time was arranged.

\section{Questionnaires}

Questionnaires were mailed out to 125 key representatives of the partnerships. These were developed based on 8 theoretical approaches that inform an understanding of partnerships (Laing and others 2009). These approaches were predominantly from the areas of institutional analysis and development framework, social-capital theory, network theory, and environmental-dispute resolution. Most questions were derived from $\geq 2$ theoretical perspectives and explored partnership features, outcomes, and factors that might contribute to outcomes and all were closed to 
permit easier quantification. Questions relating to sustainable-tourism outcomes of partnerships were based on characteristics of sustainable tourism proposed by UNEP and WTA (2005). The 14 questions covered Macbeth's categories (1994) of ecological, social, cultural, and economic sustainability.

Partnership features were investigated through 44 questions developed as a result of analysis of the above-mentioned theoretical approaches (Laing and others 2009). The questions were grouped under three categories as suggested by Bingham (1986): (1) 12 were partner related (features of the partners or partnership), e.g., empathy between partners; (2) 20 were process related (features of working together), e.g., partners aim for consensus when making decisions; and (3) 12 were context related (features of the working environment), e.g., shared accountability for decisionmaking. Respondents were asked to indicate whether these features were present (yes/no) and to rate their importance for achieving successful outcomes on a scale of 1 to 5 , with 5 being extremely important. A further 28 questions were related to outcomes of the partnership: 14 were related to general partnership outcomes, e.g., improved relationships with other partners, and 14 were related to sustainable tourism, e.g., greater respect for culture, heritage, and/or traditions. For each question, respondents were asked to rate the level of importance of the outcome and their degree of satisfaction that the outcome had been achieved. A draft version of the questionnaire was pilot tested and revised before it was posted to study participants.

\section{Interviews}

When questionnaires were returned, a personal interview was conducted with each respondent to explore in depth the features and outcomes of partnerships. Most interviews were conducted face-to-face, and a few were conducted by phone. Respondents were asked about the features of the partnership, the sustainability outcomes they thought were most important, and the factors they believed contributed to the presence (or absence) of those outcomes. Interviews were digitally recorded, and notes were taken. A summary of each interviewee's responses was sent to them to check for accuracy.

\section{Data Analysis}

Questionnaire results were entered and analysed using SPSS 15 for Windows (SPSS, Chicago, IL). Basic descriptive and bivariate statistics (e.g., frequencies, means, Student $t$ tests, correlations) were then produced for the scaled responses and closed-ended questions. Questions were scaled from "not at all important" to "extremely important." Paired Student $t$ tests were used to determine the significance of the "gap" between satisfaction and importance for the 14 sustainable-tourism outcomes (Oh 2000; Tonge and Moore 2007). To examine the relationships between the importance of features of partnerships with satisfaction with sustainable outcomes, Pearson's correlation analysis was undertaken. Features were only included where the respondent noted the feature as being present in the partnership. The correlations between the importance scores of each of the 44 features and each of the 14 partnership outcomes were examined, giving a total of 616 correlations. Correlation analysis of the satisfaction scores for the 14 general partnership outcomes was also conducted against outcomes for sustainable tourism, yielding a total of 196 correlations. Correlations that were significant at the $P<0.05$ level with $r=0.50$ and above indicated strong relationships. Correlations with $r>0.30$ and those with $r<0.50$ indicated moderate relationships, and those with $r<0.3$ indicated weak relationships (FitzGibbon and Morris 1987). Because the data in this study did not show a normal distribution, interpretation of the results requires caution; they show associations between variables rather than causality.

Qualitative results from interviews were analysed by constructing Excel spreadsheets (Microsoft, Redmond, WA). In the first round of analysis, the spreadsheets were organized around the pre-existing features listed in the questionnaire (e.g., access to influential people and/or organizations) and around the outcomes (e.g., improved biodiversity conservation in the protected area). If a feature was identified as being important by the respondent, the text block from the interview transcript was entered in the next column. Similarly, text blocks were entered for factors identified as contributing to the presence of this feature and for important outcomes as well as what contributed to them. In more complex responses, multiple text blocks were derived. A total of approximately 1,800 text blocks was obtained. In a second round of analysis, each text block was classified on the basis of themes and factors informed by the researcher's knowledge of the relevant literature.

Initially, one member of the research team analysed the text blocks and assigned each to a theme. These themes were then rationalized to give 19 , each of which was given a descriptive label and a brief explanation. These are subsequently termed "factors." In some cases, when text blocks crossed over multiple factors, they were coded according to the most useful or explanatory component. A second researcher then conducted an independent crossvalidation (Richards 2005) of every tenth entry, and a third researcher coded one fifth of the interview questions. Because the level of consistency was approximately $72 \%$, the original classification was re-examined. In most instances, this involved constructing a more detailed description of the factors and changing a few of their 
Table 2 Factor labels used for categorisation of interview responses

\begin{tabular}{llll}
\hline 1 & Adaptability and innovation & 11 & Leadership \\
2 & Individuals & 12 & Performance \\
3 & Benefits & 13 & Processes \\
4 & Commitment & 14 & Regulations and agreements \\
5 & Communication & 15 & Resources \\
6 & Continuity & 16 & Roles and powers \\
7 & Direction & 17 & Transparency and accountability \\
8 & Expertise & 18 & Trust \\
9 & Inclusion & 19 & Understanding \\
10 & Interconnections & & \\
\hline
\end{tabular}

names. The revised set of factors (Table 2) was then used for recoding. Rechecking the coding yielded approximately 90\% consistency. The researcher who conducted the original coding then checked and resolved inconsistencies.

This process decreased the number of categories from the 44 items describing the features contributing to partnerships and the 28 possible outcomes to a more manageable size and made the analysis tighter and more focused. The detail beneath the categorization was still maintained. It also meant that analysis was being based on themes and factors that emerged from the interviews as well as informed by the theory of partnerships.

\section{Results}

Of the 125 questionnaires sent out, 100 were completed, yielding a response rate of $80 \%$ ( 25 nonresponses). Interviews were then conducted with 97 of these respondents ( 3 were unable to be interviewed). The affiliations of respondents who were interviewed are listed in Table 3. Respondents were largely drawn from commercial tourism businesses or

Table 3 Affiliation of respondents

\begin{tabular}{lr}
\hline Affiliation & No. \\
\hline $\begin{array}{l}\text { Commercial tourism business (including } \\
\quad \text { accommodation, tours, etc.) }\end{array}$ & 28 \\
Regional tourism organization & 3 \\
State tourism organization & 2 \\
Protected-area government agency & 38 \\
Government agency & 3 \\
$\quad$ (not protected area or tourism) & \\
Local government authority & 6 \\
Nongovernment organization & 9 \\
$\quad$ (including "friends" of various & \\
parks and environmental organizations) & \\
Local people (including volunteers) & 5 \\
Indigenous & 1 \\
University & 2 \\
Total & 97 \\
\hline
\end{tabular}

protected-area agencies, reflecting the dominant paradigm for tourism partnerships within protected areas.

\section{Questionnaires}

When asked to indicate the importance of possible outcomes for sustainable tourism, respondents rated all as somewhat to extremely important, with scores of 3.73 $(3=$ somewhat important $)$ to $4.44(5=$ extremely important) (Table 4). Those that were most important were as follows: improved understanding of the values of protected areas by partners; improved biodiversity conservation in the protected area; and greater respect for culture, heritage, and/or traditions (as described by Laing and others 2009). Satisfaction with these outcomes also rated highly (3.51-4.24) (Table 4), with the most important outcome (i.e., improved understanding of the values of protected areas by partners) also having the highest satisfaction score. However, when the gap between satisfaction and importance was calculated, negative values were obtained for 12 of the 14 items, indicating that satisfaction with their achievement was less than their importance rating.

The only outcome for which satisfaction was significantly greater than importance was improved competitiveness of the protected area as a tourist destination, which had a positive gap of 0.29 . Satisfaction with and importance of increased prosperity of the local community indicated no significant difference. The largest significant difference between satisfaction and importance was for improved quality of environmental conditions, indicating that this item has the greatest opportunity for improvement.

Interviews

Respondents were asked to identify the two to three most important outcomes (occasionally up to four when the last factor had an equal frequency with another) of their partnership for sustainable tourism and explain how the partnership contributed to them. The three most frequently nominated factors are listed in Table 5 for each outcome. 
Table 4 The gap between satisfaction and importance of partnership outcomes for sustainable tourism

\begin{tabular}{|c|c|c|c|}
\hline Outcome & $\begin{array}{l}\text { Satisfaction } \\
\text { mean }\end{array}$ & $\begin{array}{l}\text { Importance } \\
\text { mean }\end{array}$ & Gap \\
\hline Improved understanding of the values of protected areas by partners & 4.24 & 4.46 & $-0.22^{\mathrm{a}}$ \\
\hline Improved biodiversity conservation in the protected area & 4.11 & 4.44 & $-0.33^{\mathrm{a}}$ \\
\hline Greater respect for culture, heritage, and/or traditions & 4.10 & 4.42 & $-0.32^{\mathrm{a}}$ \\
\hline Improved quality of environmental conditions & 3.78 & 4.31 & $-0.53^{\mathrm{a}}$ \\
\hline Enhancement of culture, heritage, and/or traditions & 3.91 & 4.24 & $-0.33^{\mathrm{a}}$ \\
\hline Increased social benefits to local communities & 4.13 & 4.20 & -0.07 \\
\hline Increased engagement of the local community in tourism & 4.17 & 4.20 & -0.03 \\
\hline Increased prosperity of the local community & 4.13 & 4.09 & 0.04 \\
\hline Decreased waste by visitors & 3.68 & 4.03 & $-0.35^{\mathrm{a}}$ \\
\hline Improved economic viability of the protected area & 3.95 & 3.99 & -0.04 \\
\hline Decreased use of energy & 3.57 & 3.91 & $-0.34^{\mathrm{a}}$ \\
\hline Decreased waste by tourism enterprises & 3.54 & 3.91 & $-0.37^{\mathrm{a}}$ \\
\hline Decreased use of water & 3.51 & 3.77 & $-0.26^{\mathrm{a}}$ \\
\hline Improved competitiveness of the protected area as a tourist destination & 4.02 & 3.73 & $0.29^{\mathrm{a}}$ \\
\hline
\end{tabular}

Listed according to importance mean

${ }^{\text {a }}$ Significant at $P<0.05$ as calculated using paired Student $t$ tests

The outcomes most frequently identified as important were as follows: improved understanding of the values of protected areas by partners; improved biodiversity conservation in the protected area; and increased social benefits to local communities (Table 5). Increased economic viability of the protected area, increased local prosperity, and community engagement in tourism were the next most important outcomes for sustainable tourism. Only a small number of respondents identified "brown" outcomes, e.g., reducing resource use (energy and water) and waste production, as most important. Of these, those that referred to the existence of managed accommodation supplied with alternative sources of energy placed a high priority on sustainable buildings as part of their enterprise. The factors that were nominated most frequently overall as contributing to sustainable-tourism outcomes were benefits, understanding, interconnections, and performance (Table 6). Further details from the interview text blocks yielded insight into each of the outcomes for sustainable tourism, and these will now be described in order of their importance.

\section{Enhanced Understanding of Protected-Area Values}

A desire to promote understanding of the importance of protected areas was in most instances a significant driving force. For some individuals, such as guides, the purpose was "education about the values, not only the values of protected areas but also private land, aboriginal culture, and so forth." A member of a government department responsible for environment said:

The more people you bring there, the more chance of values and respect for culture being passed on. Parks are for people, not just bits of land locked up for conservation purposes. There will be more knowledge and respect for the environment, the more people are exposed to it.

Improved understanding of protected area values was also important because it resulted in further benefits to partners. For one interviewee, tourism produced:

...a "halo effect" gives a positive experience to an influential group so they become advocates back in the community. This sets the standard for people to live up to. This improved understanding of values flows from knowledge exchange from guides to guests and includes respect for culture, heritage, and traditions.

Interest in the protected area by visitors led to a greater appreciation of it. In one instance, tourism led to greater environmental protection with extension of its most protected zone. In another, tourism led to filming by National Geographic.

A number of interviewees noted that recognizing interconnections between environmental, social, and economic aspects of the partnership promoted greater understanding of protected area values. For example, a tourism lodge manager said: 
Table 5 Summary of interview results for most important outcomes for sustainable tourism and factors contributing to them

${ }^{a}$ Results for waste production by tourism enterprises and by visitors were combined

\begin{tabular}{|c|c|c|}
\hline Outcome & $\begin{array}{l}\text { No. of } \\
\text { responses }\end{array}$ & Contributing factors \\
\hline $\begin{array}{l}\text { Improved understanding of the values } \\
\text { of protected areas by partners }\end{array}$ & 36 & $\begin{array}{l}\text { Understanding } \\
\text { Interconnection } \\
\text { Benefits/commitment }\end{array}$ \\
\hline $\begin{array}{l}\text { Improved biodiversity conservation } \\
\text { in the protected area }\end{array}$ & 24 & $\begin{array}{l}\text { Understanding } \\
\text { Performance } \\
\text { Interconnections/communication/ } \\
\text { direction }\end{array}$ \\
\hline Increased social benefits to local communities & 22 & Benefits/performance/interconnections \\
\hline Improved economic viability of the protected area & 18 & Interconnections/benefits \\
\hline Increased prosperity of the local community & 18 & $\begin{array}{l}\text { Benefits } \\
\text { Performance }\end{array}$ \\
\hline $\begin{array}{l}\text { Increased engagement of the local community } \\
\text { in tourism }\end{array}$ & 18 & $\begin{array}{l}\text { Inclusion } \\
\text { Benefits } \\
\text { Understanding }\end{array}$ \\
\hline $\begin{array}{l}\text { Greater respect for culture, heritage, } \\
\text { and/or traditions }\end{array}$ & 18 & $\begin{array}{l}\text { Understanding } \\
\text { Performance } \\
\text { Direction }\end{array}$ \\
\hline Improved quality of environmental conditions & 15 & $\begin{array}{l}\text { Performance } \\
\text { Benefits }\end{array}$ \\
\hline $\begin{array}{l}\text { Improved competitiveness of the protected } \\
\text { area as a tourist destination }\end{array}$ & 9 & Performance \\
\hline Decreased waste by tourism ${ }^{\mathrm{a}}$ & 8 & $\begin{array}{l}\text { Benefits } \\
\text { Understanding }\end{array}$ \\
\hline Decreased use of energy & 5 & Benefits \\
\hline $\begin{array}{l}\text { Enhancement of culture, heritage, } \\
\text { and/or traditions }\end{array}$ & 4 & $\begin{array}{l}\text { Interconnections/regulations and } \\
\text { agreements/direction/processes }\end{array}$ \\
\hline Unclassified & 3 & Interconnection/benefits \\
\hline Decreased use of water & 3 & Benefits/performance \\
\hline Total & 201 & \\
\hline
\end{tabular}

Table 6 Factors contributing to outcomes for sustainable tourism as indicated in interviews

\begin{tabular}{ll}
\hline Factors & No. of responses \\
\hline Benefits & 51 \\
Understanding & 32 \\
Interconnections & 27 \\
Performance & 22 \\
Inclusion & 13 \\
Direction & 10 \\
Commitment & 9 \\
Communication & 6 \\
Regulations and agreements & 6 \\
Resources & 3 \\
\hline
\end{tabular}

Seeing that a great park and walk has direct impacts and priority for businesses-It has provided opportunities to build capacity and demand for partner businesses.

\section{Improved Biodiversity Conservation}

Improved biodiversity conservation was important both for its environmental benefit and because it led to other outcomes. As conservation improved, visitation increased. At the same time, there was an increase in awareness of the frequency and abundance of species populations, location of sensitive species, fire regimes, and aims of protectedarea agencies. As sustainable tourism increased, the local community also gained more knowledge of the area and received a variety of social and economic benefits.

The performance of the partnership was critical to improving biodiversity conservation. In a number of partnerships, members contributed directly to biodiversity conservation through monitoring by volunteers, visitor education, promoting responsible visitor behaviour, and implementing sustainable management. For example, a leading representative of a government organization claimed that: 
... the country is now in the best condition of any (of its type) in the world because of managementclosing dams and getting rid of herbivore pressure on the environment, and the bird and animal numbers have shot up through the roof.

\section{A Commercial Tourism Operator Stated}

We don't leave a footprint, i.e., make sure there is no litter, recycle things aboard vessels, and create no waste. National parks initiated the boardwalks because they were concerned about erosion of the river banks. They [originally] wanted to slow boats down to stop this, so we compromised with the building of the boardwalks to enable passengers to walk through part of the forest.

\section{Social Benefits for the Local Community}

An increase in local social benefits was the third most important outcome for sustainable tourism. Pride in the local area increased through seeing the work and value of the partnership and local business stimulated through visitors use of food and other retail outlets. Partnerships also facilitated productive interactions with other tourism operators.

A number of social benefits resulted from other benefits of partnership activities, in particular from increased economic viability of the area and local prosperity. These were ascribed to the growth of tourism, building business and retail capacity and income, increased employment and tourism infrastructure and, as indicated by the Queenscliff Harbour partnership, "investing in the look and feel of the place."

The interconnections between visitors, other tourism operators, and providers also contributed social benefits. For example:

... the increase in the right sort of visitors (people that want to look after the area) to the area has been encouraged by the type of development and the associated supporting marketing materials.

\section{Other Important Outcomes}

Cited by equal numbers of interviewees were improved economic viability of the protected area, increased prosperity of the local community, and increased local tourism engagement and greater respect for culture, heritage, and/or traditions. As one interviewee stated:

Those protected areas that are economically valuable are those supported by the government. The more you do that, the more they will be conserved. Those parks that are significant economically are valuable to Australia. It would be nice if this were not the case, but that's the way it is.

Economic viability was also important because it provided the means to improve environmental management to finance better marketing, thereby increasing visitation, which in turn had flow-on effects in achieving increased engagement in local tourism and prosperity of the local community. A typical response was that economic viability was:

Particularly important for those living in regions affected by fire or drought - need to keep them there and not moving to the cities, so places don't become ghost towns. One way for the regions to stay economically viable is through tourism. It keeps people involved in their community. We are moving away from [local] people disliking tourists. By being engaged with tourism, it gives [locals] ownership over their area. They flourish across all sectors, not just business.

Factors contributing to greater respect for culture, heritage, and/or traditions were largely related to increased understanding derived from working with partners, some indigenous, who could pass on knowledge of traditions and heritage to others, including visitors and the local community.

\section{Comparison of Results from Questionnaires} and Interviews

Although improved understanding of the values of protected areas by partners and improved biodiversity conservation were identified as the two most important sustainability outcomes by both questionnaires and interviews (Table 7), there were some differences. Third and 4 th ranked items for the interviews were increased social benefits to local communities (6th on questionnaire) and improved economic viability of the protected area (10th on questionnaire). In questionnaires, 3rd- and 4th-ranked items were greater respect for culture, heritage, and/or traditions (7th in interviews) and improved quality of environmental conditions (ranked 8th in interviews).

\section{Relationships Between Sustainable Tourism Outcomes and Features of Partnerships}

The most notable finding from analysis of correlations between satisfaction scores for sustainable-tourism outcomes and importance scores for partnership features was just how few relationships there were. Correlations ranged between 0.399 and -0.318 , with 37 that were statistically 
Table 7 Comparison of results from questionnaire and interviews regarding most important sustainable-tourism outcomes

\begin{tabular}{|c|c|c|c|}
\hline \multirow[t]{2}{*}{ Sustainable-tourism outcomes } & \multicolumn{2}{|c|}{ Overall importance ranking based on } & \multirow{2}{*}{$\begin{array}{l}\text { Comparisons } \\
\text { of rankings }\end{array}$} \\
\hline & $\begin{array}{l}\text { Respondents mean } \\
\text { scores (questionnaires } \\
n=100)^{\mathrm{a}}\end{array}$ & $\begin{array}{l}\text { Frequency with which they } \\
\text { were identified as top two or } \\
\text { three (interviews } n=97 \text { ) }\end{array}$ & \\
\hline Improved understanding of the values of PAs by partners & 1 & 1 & Identical \\
\hline Improved biodiversity conservation in the PA & 2 & 2 & Identical \\
\hline Greater respect for culture, heritage, and/or traditions & 3 & 4 & Top five in both \\
\hline Improved quality of environmental conditions & 4 & 8 & - \\
\hline Enhancement of culture, heritage, and/or traditions & 5 & 12 & - \\
\hline
\end{tabular}

$P A$ Protected area

${ }^{\text {a }}$ These are ranked out of 14 given that 14 sustainable-tourism outcomes were listed in the questionnaire

significant (at $P<0.05$ ) or $6 \%$ of the total of a 616 possible correlations (Table 8 ). Of these, 5 were significant at the $P<0.01$ level. Whilst the correlations could not be regarded as strong, some important trends can be seen.

Overall, the majority of partnership features associated with sustainable-tourism outcomes were related to the contextual environment in which partnerships operated, with administrative and organizational support showing the highest and most significant correlations. Features associated with the tourism outcome regarded as most important and with which there was most satisfaction, i.e., improved understanding of protected area values, were associated with shared accountability, adequate legal frameworks that were recognized by the partnership, and existence of organizational and financial support. Adequate administrative arrangements to support tourism showed low to moderate significant correlations with the greatest number of sustainable-tourism outcomes.

In contrast, features related to partners rather than the partnership itself correlated with several sustainable-tourism outcomes. In particular, outcomes associated with local communities showed weak correlations with features, such as inclusiveness, participation, leadership, and having a supportive protected-area agency. The "brown" aspects of tourism, decreased waste and water use, were positively associated with administrative and legislative features. However, a puzzling finding was the negative association between them and trust and flexibility in decision making. Further research is needed to understand why more flexible partnerships are worse at managing waste and water use. The length of time a partnership had operated was associated with improved economic viability of the protected area and enhancement of culture and traditions, aspects of partnerships that would not necessarily develop or be recognized in the short term.

Examination of relationships between satisfaction with outcomes for sustainable tourism and for general partnership outcomes showed 39 Pearson correlation coefficients, out of the 196 correlations, that were significant $(P<0.01)$. Because the coefficients were all moderate to low, only moderate $(r>0.3)$ correlations are listed in Table 9. As would be expected, those related to economic gain as a tourism outcome were largely associated with financial aspects of the general partnership outcome. Improved access to funding from the partnership for the protected area or for the other partners showed significant correlations with 8 different sustainable-tourism outcomes. These outcomes included improvements in conservation, social benefits, environmental conditions, and decreased waste and water use. Improved understanding of protectedarea values and increased social benefits for local communities each showed significant correlations with satisfaction with four general partnership outcomes. Other general partnership outcomes yielding two significant correlations with tourism outcomes were benefits to all, stimulation of innovative approaches, strengthening organizational or business capacity, decrease of conflict, and development of new relationships with influential people or organizations.

\section{Discussion}

Through using both qualitative and quantitative methods and basing questions on eight established theoretical approaches to understanding partnerships, this research offers a detailed understanding of goals and outcomes of tourism partnerships in protected areas. It shows that achievement of sustainability goals was important to members of such partnerships, with the most important being improved understanding of the values of protected areas and improved biodiversity conservation. Gap analysis showed that although partners were largely satisfied with levels of goal achievement, there was a need for improvement. Characteristics of partnerships associated with the ability to achieve sustainability goals were 


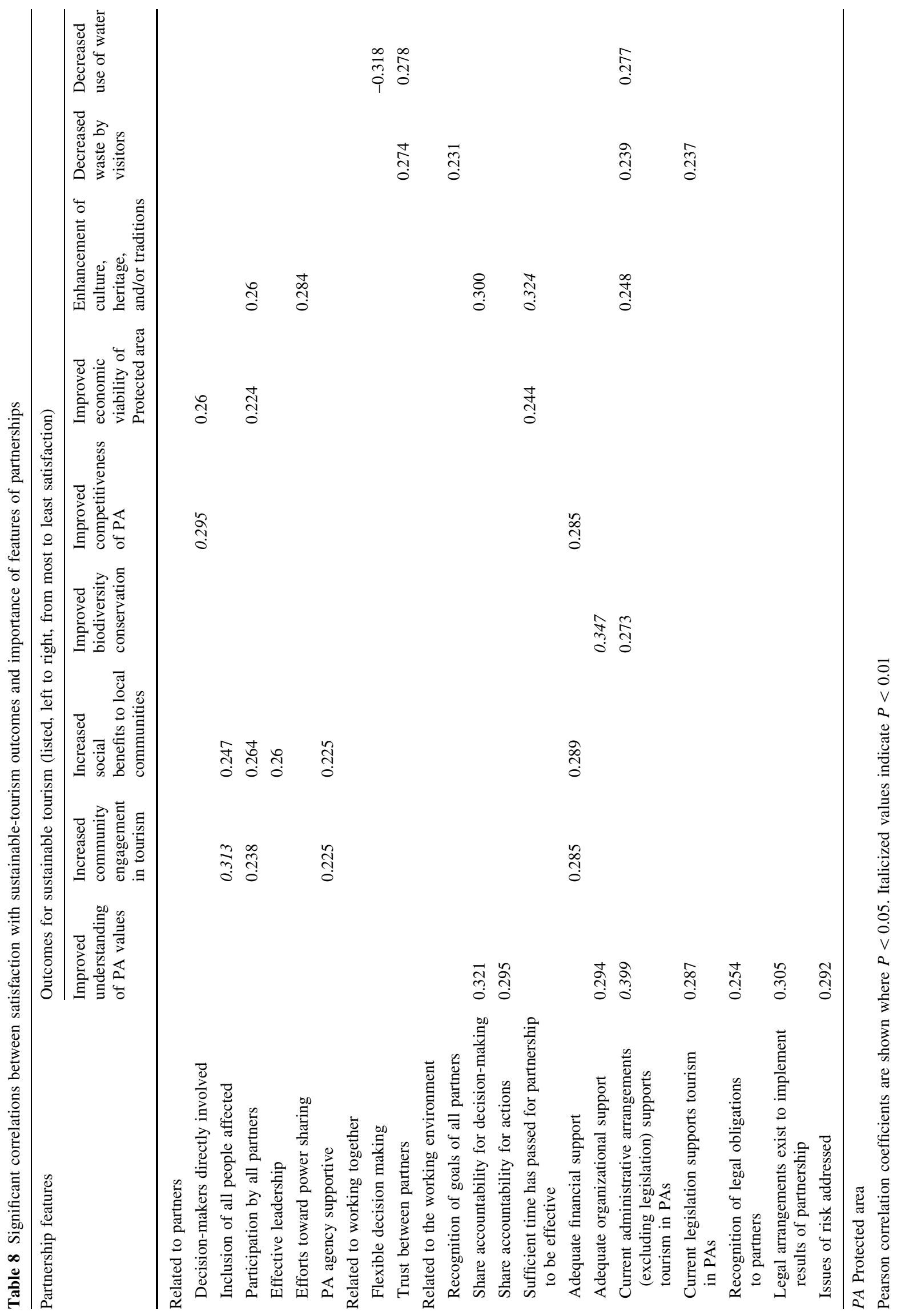




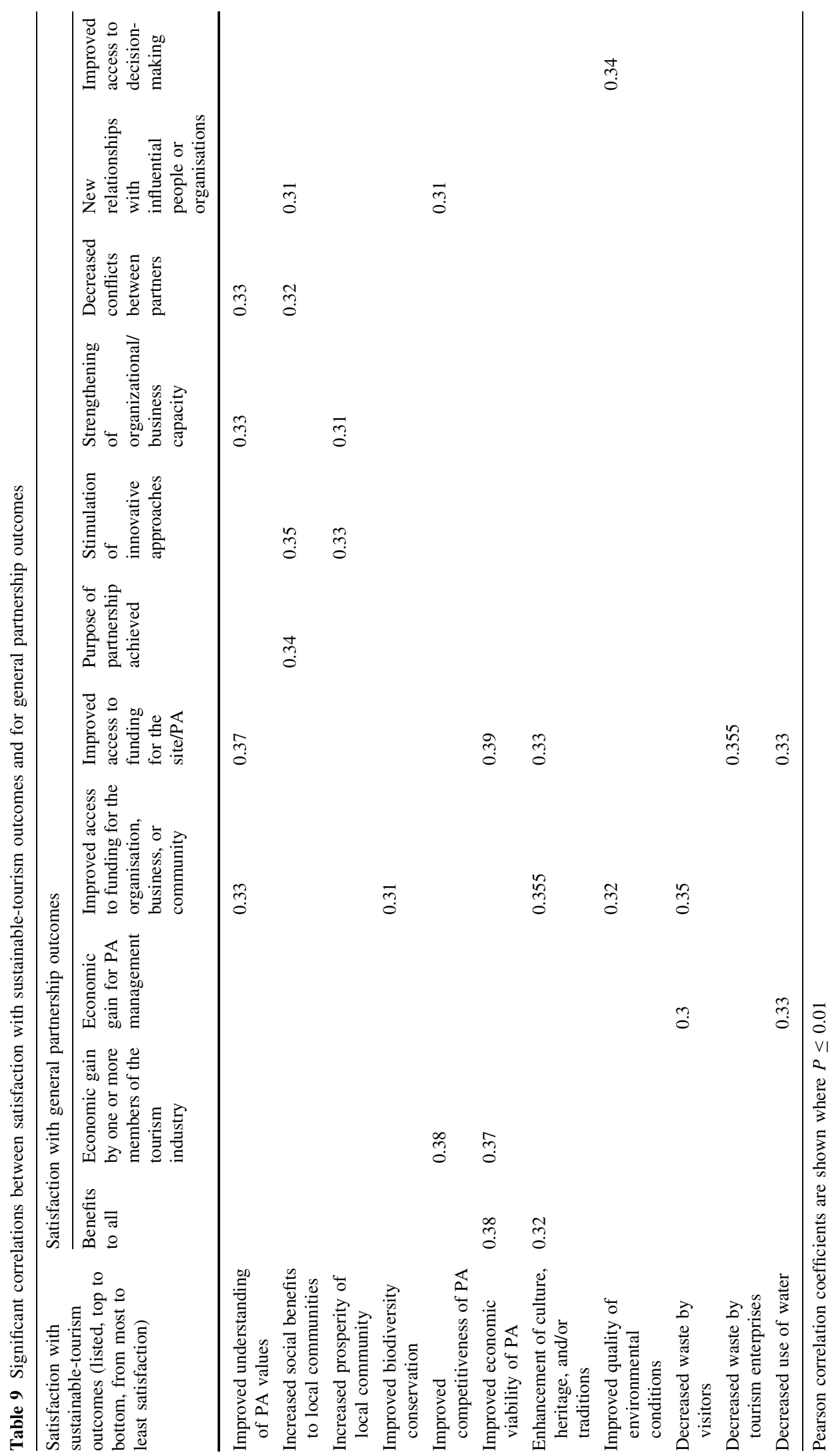


primarily provision of social and economic benefits to partners, improved understanding and increasing interconnections between partners and provision of administrative and organizational support. Data from interviews adds rich insights not obtainable through questionnaires.

Because our study focused on partnerships in protected areas, it is not surprising that the two most important outcomes for achieving sustainable tourism in both questionnaires and interviews are related to protected area values and biodiversity conservation. Respondents are according these ecocentric goals a greater priority than those of a more anthropocentric, financial, and social nature. These findings differ somewhat from other research where economic benefits for the protected area outweighed those for raised awareness of protected-area values (Steffen 2003; TTF Australia 2004). This may be a result of the differences in approaches employed in these studies. It might also reflect the fact that $58 \%$ of the respondents in this research were drawn from government or conservation-related nongovernment bodies. Further research on comparisons of responses from commercial tourism, surrounding communities, and other partnership members might explore these differences in more detail but is beyond the scope of this article. These and other studies also identify greater quality visitor experiences (Steffen 2003; Griffin and Vacaflores 2004; TTF Australia 2004) as well as public education and heightened appreciation for the need for conservation (Steffen 2003; TTF Australia 2004) as important outcomes.

The next most important sustainability outcomes differed between questionnaires and interviews. These differences reflect the capacity of interview approach to allow respondents more flexibility in discussing questions than is possible with closed questionnaire items. It is also possible that presentation of a list of possible tourism outcomes in the questionnaire prompted respondents to place greater levels of importance on more altruistic goals, such as greater respect for culture, heritage, and/or traditions and enhancement of culture, heritage, and/or traditions, which may not come immediately to respondents' minds during interviews. Together, these results reflect some of the generally accepted goals of sustainable tourism and the widespread perspective that tourism should be economically viable as well as sustain the natural environment and social aspects of associated communities (Swarbrooke 1999). It is clear, however, that in both data sets these tourism outcomes are regarded as more important than "brown" resource efficiency aspects of sustainability, such as decreased waste or energy use. A similar low regard for such aspects of tourism has been reported by others (Tonge and others 2005). It seems that members of tourism partnerships are focusing more on local benefits in improving biodiversity and the socio-cultural aspects of communities than on "bigger-picture" issues of resource use and contribution to greenhouse gas emissions, for which effects are more distant in both time and space. Thus, proposals to use biophysical productivity and waste assimilation capacity as indicators of sustainable tourism (Hunter and Shaw 2005) appear to be far from being realised.

Of the four sustainable-tourism outcomes regarded as most important from questionnaires, three are accorded the highest satisfaction scores (refer to Table 4). Although all sustainable-tourism outcomes show high importance and satisfaction scores, satisfaction is less than importance for the majority. This could be because although outcomes are regarded as important, they are less well achieved, or because respondents have high expectations that outstrip performance. Improvement in the quality of environmental conditions, the fourth most important outcome, had the highest gap between importance and satisfaction. This underscores the need to give more attention to sustainable management of land and water, perhaps through improving infrastructure in national parks and associated tourism operations and developing strategies to decrease visitor impacts. The only outcome for which the satisfaction score exceeded that for importance was increased competitiveness of the area as a tourist destination, which might be explained by previous observations that partnerships improve tourist infrastructure as well as assets and products and the quality of visitor experiences (Steffen 2003; Griffin and Vacaflores 2004; TTF Australia 2004).

Characteristics of partnerships that enable sustainability goals to be achieved when explored through interviews relate primarily to provision of a range of benefits (Table 6). Although analysis of correlations between questionnaire responses (Table 8) shows only moderate associations between outcomes and partnership features, which do not permit definitive conclusions, some interesting trends can be seen. Improved access to financial support shows the greatest number of correlations and is consistent with interview results that financial support is a benefit. This supports a study that found that partnerships with the tourism industry assisted parks in gaining funding and revenue to provide better infrastructure and assets (Steffen 2003). Buckley and Sommer (2001) also identify access to funds as an important factor. It is of interest that this is also a success factor in watershed partnerships (Leach and Pelkey 2001) where partners are not conducting a commercial enterprise, such as tourism. Similar findings were obtained by de Lacy and others (2002) and by Steffen (2003), who highlight efficiency and productivity outcomes when exploring tourism-partnership success. In those studies, benefits are also not necessarily financial but include special arrangements with natural-area managers.

The next most frequently cited factors contributing to sustainable-tourism outcomes in interviews are increased 
understanding of partners goals and the interconnections that evolve during the partnership (Table 6). This confirms previous research that identifies understanding as critical in recognising partners goals in tourism partnerships (Buckley and Sommer 2001) and in respecting varying perspectives on problems in a range of other types of partnerships (McGinnis and others 1999; Steffen 2004).

Again, interview results show several differences from questionnaire results, possibly due to differences in the way questions were posed. Interviews asked respondents directly about the aspect of partnerships that are most important to achieving sustainability goals, whereas questionnaire results were obtained by analysis of correlations. Apart from improvement in financial support addressed previously, the characteristics emerging are inclusion, supportive organisational and administrative arrangements, and direct involvement of decision makers, which are the three partner-related features rated as most important for overall partnership success (Laing and others 2009). Other characteristics related to sustainable outcomes are partnership maturity, new relationships, decrease of conflict, and stimulation of innovation. These findings support those of Mattessich and Monsey (1992) and Leach and Pelkey (2001) who find that including an appropriate range of stakeholders is vital for collaborative initiatives unrelated to tourism. In the context of both tourism (Steffen 2004) and watershed partnerships (McGinnis and others 1999), understanding the perspectives of other partners is an important success factor, whereas decrease of conflict is highlighted in a range of partnership settings (Leach and Pelkey 2001; de Lacy and others 2002; Himmelman 1996; Mohr and Spekman 1994; Poncelet 2004; Brinkerhoff 2002). The process for decreasing conflict is helpful in promoting innovative approaches to solving problems (Tremblay 2000). In studies of tourism partnerships, Buckley and Sommer (2001) and Bahaire and Elliott-White (1999) note the importance of administrative and organisational support, generally an important factor in natural-resource management (Wondolleck and Yaffee 2000). The long-standing nature of a partnership is also a recognised contributor to successful naturalresource management partnerships (Wondolleck and Yaffee 2000; Leach and Pelkey 2001; Poncelet 2004; Imperial 1999).

It is of interest that a number of "success" factors of partnerships, such as open communication, trust, and commitment, which are characteristics of the way partners work together as described by others (e.g., Laing and others 2009; Wondolleck and Yaffee 2000; Leach and Pelkey 2001; Mohr and Spekman 1994), show no significant positive correlations with satisfaction with sustainabletourism outcomes. It may be that it is possible to achieve partnership outcomes related to sustainability through structural and administrative components without much reliance on the interpersonal factors that appear important for overall partnership success.

\section{Conclusion}

Overall, our results indicate that even though tourism is a commercial activity with recognized impacts on protected areas, members of partnerships involving it believe that partnerships make considerable contributions to biodiversity conservation and environmental management. Such partnerships are most successful at increasing understanding of the values of protected areas and providing social and economic benefits to local communities. They also lead to improved visitor experiences. These partnerships are therefore demonstrating many of the characteristics ascribed to sustainable tourism. Although members of partnerships are largely satisfied with achievement of sustainable-tourism goals, they seem to think there is need for improvement. This is particularly the case with reducing waste and energy and resource use. The reasons for this are not apparent, and future research should explore whether lack of interest, time, or capacity is to blame. It is likely that staff in agencies responsible for protected-area management and those in tourism enterprises lack the technical knowledge and skills for waste and energy management, which are rather different from those required for land, habitat, and species management or for running a tourism enterprise.

Achieving sustainable outcomes through tourism partnerships relates to their capacity to improve access to funding; to establish interconnections between stakeholders, including visitors, local communities, and major decision makers; to develop understanding; and to decrease conflict between them. It also relates to adequate administrative and organizational support; to establishing new relationships with people and organisations with influence; and to stimulating innovation. In reviewing existing partnerships and establishing new ones, both natural-area managers, members of the tourism industry, and local communities could benefit from paying explicit attention to fostering these partnership attributes. This requires appropriate personnel with time and knowledge and skills in partnership management, which ultimately means improved financial support.

Acknowledgments The Sustainable Tourism Cooperative Research Centre, established and supported under the Australian Government's Cooperative Research Centres Program, funded this research. The authors also thank Sue Moore (Murdoch University), Michael Lockwood (University of Tasmania), Aggie Wegner (Charles Sturt University), and Betty Weiler and Glen Croy (Tourism Research Unit, Monash University) for their insightful inputs. 
Open Access This article is distributed under the terms of the Creative Commons Attribution Noncommercial License which permits any noncommercial use, distribution, and reproduction in any medium, provided the original author(s) and source are credited.

\section{References}

Australia Tourism and Transport Forum (2004) A natural partnership: making national parks a tourism priority. TTF Australia, Sydney

Bahaire T, Elliott-White M (1999) Community participation in tourism planning and development in the historic city of York, England. Current Issues in Tourism 2:243-276

Bingham G (1986) Resolving environmental disputes: a decade of experience. The Conservation Foundation, Washington, DC

Björk P (2007) Definition paradoxes: from concept to definition. In: Higham $\mathbf{J}$ (ed) Critical issues in ecotourism: understanding a complex tourism phenomenon. Elsevier, Oxford, pp 23-45

Blackman A, Foster F, Hyvonen T, Moscardo G (2004) Factors contributing to successful tourism development in peripheral regions. The Journal of Tourism Studies 15:59-70

Bramwell B, Henry I, Jackson G, van der Straaten J (1996) A framework for understanding sustainable tourism management. In: Bramwell W, Henry I, Jackson G, Prat AG, Richards G, van der Straaten J (eds) Sustainable tourism management: principles and practice. Tilbury University Press, Tilbury, pp 23-72

Brinkerhoff J (2002) Assessing and improving partnership relationships and outcomes: a proposed framework. Evaluation and Program Planning 25:215-231

Buckley R, Pannell J (1990) Environmental impacts of tourism and recreation in national parks and conservation reserves. Journal of Tourism Studies 1:4-32

Buckley R, Sommer M (2001) Tourism in protected areas: partnerships in principle and practice. CRC for Sustainable Tourism, Gold Coast

Butler RW (1980) The concept of a tourist-area cycle of evolution and implications for management. The Canadian Geographer 24: 5-12

Butler RW (1993) Tourism: an evolutionary perspective. In: Nelson G, Butler RW, Wall G (eds) Tourism and sustainable development: monitoring, planning, managing. University of Waterloo, Waterloo, pp 27-44

Butler RW (1996) The concept of carrying capacity for tourism destinations: dead or merely buried? Progress in Tourism and Hospitality Research 2:283-293

Butler RW (1999) Sustainable tourism: a state-of-the-art review. Tourism Geographies 1(1):7-25

Ceballos-Lascurain H (1987) The future of ecotourism. Mexico J, January:13-14

Commonwealth of Australia (2003) Australian government tourism white paper. Department of Communications, Information Technology and the Arts, Canberra

Cooper C (1996) The environmental consequences of declining destinations. Progress in Tourism and Hospitality Research 2:337-346

Davidson J, Lockwood M (2008) Partnerships as instruments of good regional governance: innovation for sustainability in Tasmania. Regional Studies 42:641-656

De Lacy T, Battig B, Moore S, Noakes S (2002) Public/private partnerships for sustainable tourism: delivering a sustainability strategy for tourism destinations. CRC for Sustainable Tourism, Gold Coast

Deery M, Jago L, Fredline L (2005) A framework for the development of social and socioeconomic indicators for sustainable tourism in communities. Tourism Review International 9:66-79
Dudley N, Gujja B, Jackson B, Jeanrenaud J-P, Oviedo G, Phillips A et al (1999) Challenges for protected areas in the 21st century. In: Stolton S, Dudley N (eds) Partnerships for protection-new strategies for planning and management for protected areas. Earthscan, London, pp 3-12

Dwyer L (2005) Relevance of triple bottom line reporting to achievement of sustainable tourism: a scoping study. Tourism Review International 9:79-93

Eadington WR, Smith VL (1992) Introduction: the emergence of alternative forms of tourism. In: Smith VL, Eadington WR (eds) Tourism alternatives: potentials and problems in the development of tourism. University of Pennsylvania Press, Philadelphia, pp 1-12

Faulkner B (2001) Destination Australia: a research agenda for 2002 and beyond. In: Faulkner HB, Fredline L, Jago L, Cooper CP (eds) Progressing tourism research. Channel View Publications, Clevedon, pp 341-357

Fitz-Gibbon CT, Morris LL (1987) How to analyze data. Sage, Newbury Park

Font X, Harris C (2004) Rethinking standards from green to sustainable. Annals of Tourism Research 31:986-1007

Goodwin H (1996) In pursuit of ecotourism. Biodiversity and Conservation 5:277-291

Gössling S, Hansson CB, Hörstmeier O, Saggel S (2002) Ecological footprint analysis as a tool to assess tourism sustainability. Ecological Economics 43:199-211

Griffin T, Vacaflores M (2004) A natural partnership: making national parks a tourism priority. Sustainable Tourism CRC, Gold Coast

Hall CM (1999) Rethinking collaboration and partnership: a public policy perspective. Journal of Sustainable Tourism 7:274-289

Hardy AL, Beeton RJS (2001) Sustainable tourism or maintainable tourism: managing resources for more than average outcomes. Journal of Sustainable Tourism 9:168-192

Himmelman AT (1996) On the theory and practice of transformational collaboration: from social service to social justice. In: Huxham C (ed) Creating collaborative advantage. Sage, London, pp 19-43

Hunter C (1997) Sustainable tourism as an adaptive paradigm. Annals of Tourism Research 24:850-867

Hunter C, Shaw J (2005) The ecological footprint as a key indicator of sustainable tourism. Tourism Management 28:46-57

Imperial MT (1999) Institutional analysis and ecosystem-based management: the institutional analysis and development framework. Environmental Management 24:449-465

International Union for Conservation of Nature/United Nations Environment Program/World Wildlife Fund (IUCN/UNEP/ WWF) (1991) Caring for the earth: a strategy for sustainable living. IUCN, Gland, Switzerland

Jones PJ, Burgess J (2005) Building partnership capacity for the collaborative management of marine protected areas in the UK: a preliminary analysis. Journal of Environmental Management 77:227-243

Kapoor I (2001) Towards participatory environmental management? Journal of Environmental Management 63:269-279

Laing JH, Lee D, Moore SA, Wegner A, Weiler B (2009) Advancing conceptual understanding of partnerships between protected area agencies and the tourism industry: a postdisciplinary and multi-theoretical approach. Journal of Sustainable Tourism 17: 207-229

Leach WD, Pelkey NW (2001) Making watershed partnerships work: a review of the empirical literature. Journal of Water Resources Planning and Management 127:378-385

Leslie D (1986) Tourism and conservation in national parks. Tourism Management 7:52-56

Macbeth J (1994) To sustain is to nurture, to nourish, to tolerate and to carry on: can tourism? Trends 31:42-45 
Macbeth J, Carson D, Northcote J (2004) Social capital, tourism and regional development: SPCC as a basis for innovation and sustainability. Current Issues in Tourism 7:502-522

Mattessich P, Monsey B (1992) Collaboration: what makes it work? Amherst H. Wilder Foundation, St Paul

McCool SF, Moisey RN, Nickerson NP (2001) What should tourism sustain? The disconnect with industry perceptions of useful indicators. Journal of Travel Research 40:124-131

McGinnis MV, Woolley J, Gamman J (1999) Bioregional conflict resolution: rebuilding community in watershed planning and organizing. Environmental Management 24:1-12

Mohr J, Spekman R (1994) Characteristics of partnership success: partnership attributes, communication behavior and conflict resolution techniques. Strategic Management Journal 15:135-152

Moore SA (1996) Defining successful environmental dispute resolution: case studies from public land planning in the United States and Australia. Environmental Impact Assessment Review 16:151-169

Moore SA, Lee RG (1999) Understanding dispute resolution processes for American and Australian public wildlands: towards a conceptual framework for managers. Environmental Management 23:453-465

Murphy PE (1986) Tourism as an agent for landscape conservation: an assessment. The Science of the Total Environment 55:387-395

Murphy PE, Price GG (2005) Tourism and sustainable development. In: Theobald WF (ed) Global tourism, 3rd edn. Elsevier, Burlington, pp 167-193

Oh H (2000) Revisiting importance-performance analysis. Tourism Management 22:617-627

Payne R (1993) Sustainable tourism: suggested indicators and monitoring techniques. In: Nelson JG, Butler RW, Wall G (eds) Tourism and sustainable development: monitoring, planning, managing. University of Waterloo, Waterloo, pp 249-254

Pigram JJ, Wahab S (1997) Sustainable tourism in a changing world. In: Wahab S, Pigram JJ (eds) Tourism, development and growth: the challenges of sustainability. Routledge, London, pp 3-32

Poncelet EC (2004) Partnering for the environment: multistakeholder collaboration in a changing world. Rowman \& Littlefield, Lanham

Rhodes RAW (1997) Understanding governance: policy networks, governance, reflexivity and accountability. Open University Press, Buckingham

Richards L (2005) Handling qualitative data-a practical guide. Sage, London

Robinson M (1999) Collaboration and cultural consent: refocusing sustainable tourism. Journal of Sustainable Tourism 7:379-397

Rosenau JN (2000) Change, complexity, and governance in globalizing space. In: Pierre J (ed) Debating governance. Oxford University Press, Oxford, pp 167-200

Saxena G (2005) Relationships, networks and the learning regions: case evidence from the Peak District National Park. Tourism Management 26:277-289

Selin S (1999) Developing a typology of sustainable tourism partnerships. Journal of Sustainable Tourism 7:260-273

Sharpley R (2000) Tourism and sustainable development: exploring the theoretical divide. Journal of Sustainable Tourism 8:1-19

Slocombe DS (1993) Implementing ecosystem-based management. Bioscience 43:612-622

Steffen C (2003) Pursuing common goals: opportunities for tourism and conservation. Department of Industry, Tourism and Resources (DITR), Canberra
Steffen C (2004) Parks and tourism partnerships: an industry perspective. In: Buckley R (ed) Tourism in parks: Australian initiatives. Griffith University, International Centre for Ecotourism Research, Gold Coast

Stubbs BJ, Specht RL (2005) Lamington National Park and Binna Burra Mountain Lodge, Queensland: partners in conserving rainforest. In: Calver M, Bigler-Cole H, Bolton G, Dargavel J, Gaynor A, Horwitz $\mathrm{P}$ et al (eds) A forest conscienceness. Proceedings of the 6th national conference of the Australian Forest History Society. Millpress, Rotterdam, pp 707-716

Sun D, Walsh D (1998) Review of studies on environmental impacts of recreation and tourism in Australia. Journal of Environmental Management 53:323-338

Swarbrooke J (1999) Sustainable tourism management. CAB International, Oxon

Tonge H, Moore SA (2007) Importance-satisfaction analysis for marine-park hinterlands: a Western Australian case study. Tourism Management 28:768-776

Tonge J, Moore SA, Hockings M, Worboys G, Bridle K (2005) Developing indicators for the sustainable management of visitor use of protected areas in Australia. Sustainable Tourism CRC, Gold Coast

Tremblay P (2000) An evolutionary interpretation of the role of collaborative partnerships in sustainable tourism. In: Bramwell B, Lane B (eds) Tourism collaboration and partnerships: politics, practice and sustainability. Channel View, Clevedon, pp 314-332

Tsaur S-H, Lin Y-C, Lin J-H (2005) Evaluating ecotourism sustainability from the integrated perspective of resource, community and tourism. Tourism Management 27:640-653

United Nations Conference on Environment and Development (UNCED) (1993) Agenda 21: the Earth Summit strategy to save our planet: United Nations Conference on Environment and Development (1992: Rio de Janeiro, Brazil). EarthPress, Boulder, Colo

United Nations Environment Programme/World Tourism Organisation (2005) Making tourism more sustainable - a guide for policy makers. Division of Technology, Industry and Economics, UNEP, Paris

Wahab S, Pigram JJ (1997) Tourism and sustainability: policy considerations. In: Wahab S, Pigram JJ (eds) Tourism, development and growth: the challenges of sustainability. Routledge, London, pp 277-290

Wall G (1997) Sustainable tourism—unsustainable development. In: Wahab S, Pigram JJ (eds) Tourism, development and growth: the challenges of sustainability. Routledge, London, pp 33-49

Wearing S, Neil J (1999) Ecotourism: impacts, potentials and possibilities. Butterworth Heinemann, Oxford

Wheeller B (1993) Sustaining the ego. Journal of Sustainable Tourism 1(2):12-129

Wight PA (1993) Sustainable ecotourism: balancing economic, environmental and social goals within an ethical framework. Journal of Tourism Studies 4:54-66

Wondolleck JM, Yaffee SL (2000) Making collaboration work: lessons from innovation in natural resource management. Island Press, Washington, DC

World Commission on Environment and Development (WCED) (1987) Our common future. Oxford University Press, Oxford

World Tourism Organization (1993) Sustainable tourism development: guide for local planners. WTO, Madrid

Yin RK (2003) Case study research: design and methods. Sage Publications, Thousand Oaks, CA 